\title{
Influence Factors Analysis of the Sustainable Development of Scientific and Technological Personnel in Tibet
}

\author{
Fan Gu \\ Institute of ideological and political theory teaching \\ Xi'an University of Architecture and Technology \\ Xi'an, China \\ e-mail: xa-gufan@163.com
}

\author{
Wen-qin Bi \\ School of Management \\ Xi'an University of Architecture and Technology \\ Xi'an, China \\ e-mail: bwq2209835@163.come
}

\begin{abstract}
-the quantitative research on the key factors affecting the development of science and technology talent. Based on grey correlation theory, the study analyze the factors that influences the sustainable development of science and technology talent in Tibet, and it discussed the various factors associated with the extent of their. For better to research the relationship of development of technology talent with GDP per capita and so affect factors. Specify the number of Tibetan technological research and service personnel as a reference data column, other data as comparative data column which includes Tibet's per capita GDP, education investment, health service investment, research expenditures, wages of research employees, the number of patents granted, the number of university students in per million people, The analysis showed that the selected indicators are scientific factors; and these factors herein are selected to sustainable development in Tibet talents played a considerable impact, just different degree of influence of different factors ; and these factors have significant effects on sustainable development of Tibet technology professionals.
\end{abstract}

Keywords-Tibet; Scientific and Technological talent; Sustainable development; Influence factor; Grey relational analysis

\section{INTRODUCTION}

Science and technology is the key to sustainable development of the national economy productivity. Science and technology talent in science and technology plays an essential rove in the technology and sustainability. Therefore, the quantitative research on the key factors affecting the development of science and technology talent has a practical mean, which could boost the development of a country or region talents resources, and constantly improve the quantity and quality of local talents, and provide a strong impetus for economic development, and promote technological innovation and to achieve sustainable economic growth .

In recent years, under the leadership of the party and the government, with the support of the whole nation, through the joint efforts of the Tibetan people, science and technology has made great progress in Tibet. In 2013, Tibet technological activities revenue amounted to
308.915 million Yuan and the expenditure amounted to 284.27 million Yuan. There are 16 research institutes, and796 researchers, and 120 research projects[1].Its research areas mainly include natural science, agricultural science, engineering, science and technology, social sciences, and humanities. In the study, it author used grey system theory which was found by the well-known scholar Deng julong in 1982[2].This research analyzed the number of research activities and researchers, and the investment amount of research activities. At last it sorted out the influencing factors of sustainable development of Tibet talents and deduced the degree of association of each influencing factors. Then, the study provided data and theoretical basis for government planning and decision-making for the scientific and technological personnel in Tibet.

\section{THE MAIN FACTORS AFFECTING THE}

DEVELOPMENT OF SCIENCE AND TECHNOLOGY TALENT ANALYSIS

\section{A. Select variables}

About the Influencing Factors to the development of science and technology talent in Tibet have many, and the size of the correlation degree and influence have needed to obtain through scientific research. We after inspection 2008-2012 "Tibet Statistical Yearbook", sorting out the relevant data[3].Grey System Theory Professor Deng Julong taken in one of the major achievements - gray correlation analysis of data available for analysis. With respect to the regression analysis, analysis of variance, principal component analysis, and so on system analysis, do not ask the number of gray correlation analysis of the data collected on the number of samples and the samples between whether the law can be applied, does not appear quantitative results and qualitative results circumstances inconsistent[4].Therefore easier to identify from a large number of indicators related to economic development in Tibet, and the key factors affecting the development of Tibet technology professionals, and thus the analysis of these factors. Specifically selected indicators as follows: 
1) Per capita GDP in Tibet: a level of economic development in the region will affect the development of science and technology talent in the region. Because of Tibet's vast and small population, so choose the per capita GDP of Tibet as a study on sustainable development indicators of technology professionals to help quantitative analysis[5].

2) Education Investment: Human Capital believes that education is the most important means to improve the human capital. More investment in education is necessary condition for the development of scientific and technological personnel to obtain good results.

3) Health service investment: Human labor, creativity depends on the person's physical fitness and health. Into healthcare can provide a strong individual quality for technology professionals.

4) Research expenditures: investment in research funding can provide a good research environment for technology professionals, and provide better scientific hardware facilities for technology professionals. Meanwhile, adequate funding to improve the scientific enthusiasm of researchers, thus achieving improve the technological level of talent.

5) Wages of research employees: hire are an important factor for attracting people to join scientific research, excitation of wages will affect the industry's choice of employment staff.

6) The number of patents granted: this year may reflect the level of innovation in Tibet, innovation environment, the level of protection of intellectual property rights, etc.

7) The number of university students in per million people: it may reflect the cultural quality and technological level of the population in a region.

Association analysis must first specify the reference data column and compare data columns. Reference number of columns denoted to $x_{0}, x_{0}=\left\{x_{0}(1), x_{0}(2), \mathrm{L} x_{0}(n)\right\}$ compare the number of columns denoted to $x_{i}, x_{i}=\left\{x_{i}(1), x_{i}(2), \mathrm{L}, x_{i}(n)\right\}, i=1,2, \mathrm{~L}, n[6]$.

Based on the findings of other researchers in science and technological talents, and the actual situation in Tibet, for better to research the relationship of development of technology talent with GDP per capita and so affect factors. Specify the number of Tibetan technological research and service personnel as a reference data columns $x_{0}$, other data as comparative data column $x_{i}$ which includes Tibet's per capita GDP, education investment, health service investment, research expenditures, wages of research employees, the number of patents granted, the number of university students in per million people, and successively marked as $x_{1}, x_{2}, x_{3}, x_{4}, x_{5}, x_{6}, x_{7}$. Through research and data compilation, the paper selected indicators and data in TABLEI below:
TABLE I. Number OF SCIENTIFIC RESEARCH AND SERVICE PERsonnel in TiBet With The Benchmark IndEX

\begin{tabular}{|l|c|c|c|c|c|}
\hline \multirow{2}{*}{$\begin{array}{l}\text { Data } \\
\text { Column }\end{array}$} & \multicolumn{5}{|c|}{ Year } \\
\hline$x_{0}$ & 6229 & 7476 & 7445 & 8128 & 12530 \\
\hline$x_{1}$ & 13824 & 15295 & 17319 & 20077 & 22936 \\
\hline$x_{2}$ & 470800 & 610441 & 607959 & 778126 & 944843 \\
\hline$x_{3}$ & 163548 & 220868 & 320406 & 35043 & 361174 \\
\hline$x_{4}$ & 29033 & 26913 & 27112 & 33800 & 50891 \\
\hline$x_{5}$ & 29075 & 34709 & 39773 & 40860 & 53424 \\
\hline$x_{6}$ & 95 & 292 & 124 & 107 & 112 \\
\hline$x_{7}$ & 102 & 104 & 104 & 104 & 107 \\
\hline
\end{tabular}

\section{B. Data processing and computing}

\section{1) Dimensionless data processing}

Because the dimension of various influencing factors is not the same in the system, it is difficult to directly compare the sample data. So the parameter sequence and compare sequence of the original data are calculated dimensionless, which make the comparability between various factors. Generally use the average method and the initial value of law [7].This article takes the initial value of the treatment, the initial value of the treatment formula:

$$
x_{i}^{\prime}(k)=x_{i}(k) / x_{i}(1), k=1,2, \mathrm{~L}, m \text {. }
$$

After the data in Table 1 is calculated dimensionless, and to derive a new number of columns in TABLEII below:

TABLE II. RESULTS DIMENSIONLESS INFORMATION TABLE

\begin{tabular}{|c|c|c|c|c|c|}
\hline \multirow{2}{*}{$\begin{array}{l}\text { Data } \\
\text { Column }\end{array}$} & \multicolumn{5}{|c|}{ Year } \\
\hline & $\mathbf{2 0 0 8}$ & $\mathbf{2 0 0 9}$ & $\mathbf{2 0 1 0}$ & $\mathbf{2 0 1 1}$ & $\mathbf{2 0 1 2}$ \\
\hline$x_{0}^{\prime}$ & 1.0000 & 1.2001 & 1.1952 & 1.3048 & 2.0115 \\
\hline$x_{1}^{\prime}$ & 1.0000 & 1.1064 & 1.2528 & 1.4523 & 1.6591 \\
\hline$x_{2}^{\prime}$ & 1.0000 & 1.2966 & 1.2913 & 1.6527 & 2.0068 \\
\hline$x_{3}^{\prime}$ & 1.0000 & 1.3504 & 1.9591 & 2.1587 & 2.2084 \\
\hline$x_{4}^{\prime}$ & 1.0000 & 0.9270 & 0.9338 & 1.1642 & 1.7529 \\
\hline$x_{5}^{\prime}$ & 1.0000 & 1.1938 & 1.3679 & 1.4053 & 1.8375 \\
\hline$x_{6}^{\prime}$ & 1.0000 & 3.0737 & 1.3052 & 1.1263 & 1.1789 \\
\hline$x_{7}^{\prime}$ & 1.0000 & 1.0196 & 1.0196 & 1.0196 & 1.0490 \\
\hline
\end{tabular}

2) Calculating the correlation coefficient

Association is essentially the difference between the curve geometry. Therefore, the size difference will be between the curves as a measure of the degree of association. To find the correlation coefficient is dimensionless number after processing sequence differential column seeking to arrive at the maximum and minimum difference $\alpha, \beta$ the formula is as follows:

$$
\alpha=\max _{i} \max _{k}\left|x_{0}(k)-x_{i}(k)\right|
$$




$$
\begin{aligned}
& \beta=\min _{i} \min _{k}\left|x_{0}(k)-x_{i}(k)\right| \\
& \Delta_{i}(k)=\left|x_{0}(k)-x_{i}(k)\right|
\end{aligned}
$$

Seeing the difference between the sequences of TABLEI, the sequence difference of the results shown in TABLEIII below:

TABLE III. NUMBER OF SCIENTIFIC RESEARCH AND INFORMATION SERVICE PERSONNEL OF TIBET AND ALL GRAY VALUE OF EACH FACTOR

\begin{tabular}{|l|c|c|c|c|c|}
\hline Column & \multicolumn{5}{|c|}{ Year } \\
\cline { 2 - 6 }$\Delta_{i}$ & $\mathbf{2 0 0 8}$ & $\mathbf{2 0 0 9}$ & $\mathbf{2 0 1 0}$ & $\mathbf{2 0 1 1}$ & $\mathbf{2 0 1 2}$ \\
\hline$\Delta_{1}$ & 0 & 0.0937 & 0.0576 & 0.1475 & 0.3524 \\
\hline$\Delta_{2}$ & 0 & 0.0965 & 0.0961 & 0.3479 & 0.0047 \\
\hline$\Delta_{3}$ & 0 & 0.1503 & 0.7639 & 0.8539 & 0.1969 \\
\hline$\Delta_{4}$ & 0 & 0.2731 & 0.2614 & 0.1406 & 0.2586 \\
\hline$\Delta_{5}$ & 0 & 0.9270 & 0.1727 & 0.1005 & 0.1740 \\
\hline$\Delta_{6}$ & 0 & 1.8736 & 0.1100 & 0.1785 & 0.8326 \\
\hline$\Delta_{7}$ & 0 & 0.1805 & 0.1756 & 0.2852 & 0.9625 \\
\hline$\Delta_{1}$ & 0 & 0.0937 & 0.0576 & 0.1475 & 0.3524 \\
\hline
\end{tabular}

Apply the Eq. (2),(3)for the number of columns in Table 1 to obtain a sequence difference, we can be drawn from the maximum $\alpha=1.8736$ and minimum $\beta=0$, and then calculate the gray correlation coefficient $x_{0}$ and $x_{i}$, the use of gray correlation coefficient calculation Equation:

$\xi_{i}(k)=\frac{\min _{i} \min _{k}\left|x_{0}(k)-x_{i}(k)\right|+\theta \max _{i} \max _{k}\left|x_{0}(k)-x_{i}(k)\right|}{\left|x_{0}(k)-x_{i}(k)\right|+\theta \max _{i} \max _{k}\left|x_{0}(k)-x_{i}(k)\right|}$

According to Eq. (2),(3),(5) gray correlation coefficient can be expressed as:

$$
\xi_{i}(k)=\frac{\beta+\theta \alpha}{\left|x_{0}(k)-x_{i}(k)\right|+\theta \alpha}
$$

$\xi_{i}(k)$ Represent the number of columns in the $k$ time comparison with the reference number of columns $x_{0}$ and $x_{i}$ relative difference. In order to reduce the impact of extreme value calculation, the introduction of resolution coefficient $\theta$, typically ranging from between $0-1$, the paper take $\theta=0.5$ [8].According to the formula (4) obtained correlation coefficient as shown in TABLEIV

TABLE IV. NUMBER OF SCIENTIFIC RESEARCH AND SERVICE PERSONNEL OF TIBET ASSOCIATED WITH EACH FACTOR COEFFICIENT GREY

\begin{tabular}{|l|l|l|l|l|l|}
\hline$\xi_{1}$ & 1 & 0.9091 & 0.9421 & 0.8640 & 0.7267 \\
\hline$\xi_{2}$ & 1 & 0.9065 & 0.9070 & 0.7292 & 0.9950 \\
\hline$\xi_{3}$ & 1 & 0.8617 & 0.5508 & 0.5231 & 0.8263 \\
\hline
\end{tabular}

\begin{tabular}{|l|l|l|l|l|l|}
\hline$\xi_{4}$ & 1 & 0.7743 & 0.7818 & 0.8695 & 0.7837 \\
\hline$\xi_{5}$ & 1 & 0.5026 & 0.8443 & 0.9031 & 0.8434 \\
\hline$\xi_{6}$ & 1 & 0.3333 & 0.8949 & 0.8400 & 0.5294 \\
\hline$\xi_{7}$ & 1 & 0.8384 & 0.8421 & 0.7666 & 0.4932 \\
\hline
\end{tabular}

\section{3) Computing related degree}

Since the gray correlation coefficient more information scattered, inconvenient to compare, so the gray correlation coefficient at each time find the average. The general expression for the gray correlation:

$$
\gamma_{i}=\frac{1}{m} \sum_{k=1}^{m} \xi_{i}(k), i=1,2 \mathrm{~L}, m
$$

Using Eq. (6) returns the gray correlation degree of each factor is shown in TABLEV:

TABLE V. NUMBER OF SCIENTIFIC RESEARCH AND SERVICE PERSONNEL OF TIBET WITH GRAY CORRELATION DEGREE OF EACH FACTOR

\begin{tabular}{|c|c|c|c|c|c|}
\hline$\gamma_{1}$ & $\gamma_{2}$ & $\gamma_{3}$ & $\gamma_{4}$ & $\gamma_{5}$ & $\gamma_{6}$ \\
\hline 0.8884 & 0.9075 & 0.7504 & 0.8419 & 0.8187 & 0.7195 \\
\hline
\end{tabular}

Sort of related degree: $\gamma_{2}>\gamma_{1}>\gamma_{4}>\gamma_{5}>\gamma_{7}>\gamma_{3}>\gamma_{6}$

According to Gray Correlation accuracy test grade reference table, associate degrees above 0.9 for first stage, from 0.8 to 0.9 for second stage, from 0.8 to 0.7 for third stage, from 0.7 to 0.6 for fourth stage. [9]Factors affecting the sustainable development of scientific and technological personnel in Tibet, the association of the investment in education are 0.9095 , reaching the highest grade level standards; per capita GDP, the scientific research funds investment, scientific research staff wages of correlation were $0.8884,0.8419$ and 0.8187 , and the correlation degree is at level 2. Number of college students per million people, health investment and the number of patents granted to associate degrees also reached three criteria were $0.7881,0.7504$ and 0.7195 .

\section{ANALYSIS RESULT}

According to the principle of gray correlation analysis, when $\theta=0.5$, the correlation is greater than 0.6 will be considered a significant correlation[10], the results show paper selected indicators are above 0.6, indicating that paper selected indicators scientific.

- The degree of association between $x_{2}$ and $x_{0}$ is the greatest, its correlation coefficient reached 0.9095 . This shows that the investment in education a significant impact on the sustainable development in Tibet talents to produce a significant impact, which directly reflects the development of Tibet technology professionals, we must focus on training and education the more professional knowledge and skills people grasp, the more quickly the research and services in Tibet could develop. 
- The correlation coefficient between $x_{1}, x_{4}, x_{5}$ and $x_{0}$ respectively are $0.8884,0.8419$ and 0.8187 . This shows that per capita GDP, the scientific research funds investment, scientific research staff wages have an obvious effect on sustainable development of Tibet science and technology talents. Therefore, importance should be attached to science and technology personnel working environment and remuneration.

- Compared to other influencing factors, the correlation between $x_{7}, x_{3}, x_{6}$ and $x_{0}$ is small, which are $0.7881 、 0.7504$ and 0.7195 . This indicates that the number of university students per million, health investment and the number of granted patents also affects the sustainable development of Tibet talents, but its relevance is less than other factors.

\section{SUMMARY}

Overall, the factors herein are selected to sustainable development in Tibet talents played a considerable impact, just different degree of influence of different factors. The greater the impact of factors related to the sustainable development of the relationship between science and technology talent in Tibet more closely; the smaller the correlation, the impact of factors and is closely related to the sustainable development of Tibet talents smaller degree.

[1] The Tibet autonomous region science and technology department, "S\&T Statistical Data of Tibet", unpublished.

[2] Deng Julong, Grey System Basis, Wuhan: Huazhong University of Science and Technology Press, 2002.

[3] Statistics prepared by the Tibet Autonomous Region, Tibet Statistical Yearbook, Beijing : China Statistics Press, 2013

[4] Liu Sifeng, Xie Siming, Grey System Theory and Its Applications, Beijing : Science Press, 2008.pp.39-41

[5] Ma Shouchun, Zhang Min, "Tibet's GDP trends and factors mathematical model, Mathematics in Practice and Theory", Vol.39, No.10, May,2009.pp.33-36.

[6] Wang Yi, Shun Jian, "The main factors affecting the development of the analysis of regional scientific and technological talents", Science\&Technology and Economy,Vol.25, No.5, Oct.2012.pp.9294.

[7] Yao Jiejing, Peng Hui, Grey Relational Analysis copyright protection and cultural industry innovation capability, J. Capital University of Economics Journal, 2011(2),pp.31-37.

[8] Du Dong, Pang QingHuan, and Wu Yan,Xie, Evaluation of modern methods and case selection, 2th ed, Beijing: Science Press, 2008.pp.89-128

[9] Liu SiFeng,Gu TianBang, and Dang YaoGuo, Grey System Theory and Its Applications, 2th ed, Beijing: Science Press, 1999, pp.135.

[10] Lie Yanfei, "Research on Evaluation Model oilfield technology professionals AHP and gray relational analysis",Master thesis, Shanghai jiaotong university, 2011. 